\title{
A musculatura epaxial e a fibrose epidural na compressão medular em cães submetidos à laminectomia dorsal modificada ${ }^{1}$
}

\author{
Diego V. Beckmann ${ }^{2 *}$, Alexandre Mazzanti ${ }^{3}$, Marina Gabriela M.C.M.Cunha ${ }^{2}$, \\ Giancarlo S. Souza ${ }^{2}$, Rafael Festugatto ${ }^{2}$, Rosmarini P. Santos ${ }^{2}$, Dakir Polidoro \\ Neto $^{4}$ e Raquel Baumhardt ${ }^{4}$
}

\begin{abstract}
Beckmann D.V., Mazzanti A., Cunha M.G.M.C.M., Souza G.S., Festugatto R., Santos R.P., Polidoro Neto D. \& Baumhardt R. 2010. [Epaxial musculature and epidural fibrosis in the spinal compression in dogs submitted modified dorsal laminectomy.] A musculatura epaxial e a fibrose epidural na compressão medular em cães submetidos à laminectomia dorsal modificada. Pesquisa Veterinária Brasileira 30(2):127-131. Departamento de Clínica de Pequenos Animais, Universidade Federal de Santa Maria, Camobi, Santa Maria, RS 97105-900, Brazil. E-mail: dvbeckmann@ hotmail.com

The purpose of this study was to isolate the adjacent epaxial musculature from exposed spinal cord by modified dorsal laminectomy in dogs with aluminum implant and to verify whether the muscles contribute to form epidural fibrosis, spinal cord compression, and development of neurological signs. Ten dogs were submitted to modified dorsal laminectomy between T13 and L1 and then distributed along two groups. Dogs in the group 1 remained with the spinal cord exposed without the implant; dogs in the group 2 had an aluminum implant inserted between the epaxial muscles and the exposed spinal cord. Neurological examination was daily performed until 180 days post surgery. Additionally, myelography at 15,30 , and 60 days post surgery and macroscopic evaluation of the implant at six months post surgery were done. There was no difference between groups in the neurological examination. A statistical difference in the degree of spinal compression was observed at day 15 post surgery in the group 2 . In this group, the epaxial musculature adjacent to the spinal cord was not in contact with the epidural fibrosis, differently to what was observed in the control group. The implant was removed easily with some degree of deformity. The results showed that the adjacent musculature of the spinal cord submitted to a modified dorsal laminectomy in dogs can be isolated by aluminum implant, without any contact with epidural fibrosis or influence in the development of neurological signs.
\end{abstract}

INDEX TERMS: Implant, laminectomy, neurosurgery, myelography, dog.

RESUMO.- O objetivo deste experimento foi isolar a musculatura epaxial da medula espinhal de cães submetidos à laminectomia dorsal modificada (LDM) e averiguar se os músculos influenciaram na formação da fibrose epidu-

\footnotetext{
${ }^{1}$ Recebido em 17 de julho de 2009.

Aceito para a publicação em 1 de outubro de 2009.

2 Programa de Pós-Graduação em Medicina Veterinária, área de concentração em Cirurgia, Centro de Ciências Rurais (CCR), Universidade Federal de Santa Maria (UFSM), Camobi, Santa Maria, RS 97105-900, Brasil. "Autor para correspondência: dvbeckmann@ hotmail.com

${ }^{3}$ Departamento de Clínica de Pequenos Animais, CCR, UFSM, Santa Maria, RS.

${ }^{4}$ Curso de Medicina Veterinária, CCR, UFSM, Santa Maria, RS.
}

ral, na compressão medular e no aparecimento dos sinais neurológicos. Para isso, dez cães hígidos foram submetidos à LDM entre as vértebras T13 e L1 e distribuídos aleatoriamente em dois grupos denominados controle (I) onde a medula espinhal permaneceu exposta sem a presença de implante, e tratado (II) onde foi colocado um implante a base de alumínio entre a musculatura epaxial adjacente e a medula espinhal exposta pela LDM. As avaliações constaram de exames neurológicos diários até 180 dias de pós-operatório (PO); mielografia, decorridos 15 , 30 e 60 dias de PO; e avaliação macroscópica mediante a reintervenção cirúrgica. Não houve diferença durante as avaliações neurológicas. Aos 15 dias de PO, foi verifi- 
cado na mielografia, que o grau de compressão da linha de contraste foi maior no grupo tratado $(P<0,05)$ quando comparado ao grupo controle, não havendo diferença dos demais tempos estudados. Na avaliação macroscópica, pode-se observar que no Grupo II, a musculatura epaxial adjacente à medula espinhal não estava em contato com a fibrose epidural, diferentemente do grupo controle. 0 implante pôde ser removido facilmente e apresentava discreto grau de deformidade crânio-dorsal. Pode-se concluir que a musculatura epaxial adjacente é isolada da medula espinhal pelo implante à base de alumínio em cães submetidos à LDM, e esta não influencia na formação da fibrose epidural, compressão medular e no aparecimento dos sinais neurológicos.

TERMOS DE INDEXAÇÃO: Implante, laminectomia, neurocirurgia, mielografia, cão.

\section{INTRODUÇÃO}

A laminectomia é um procedimento cirúrgico que permite o acesso à medula espinhal mediante a remoção dos processos espinhosos e articulares e pedículos das vértebras envolvidas. Atualmente, é indicada para o tratamento de pacientes com neoplasias envolvendo a medula espinhal e no tratamento da síndrome da cauda equina (Kalfas 2000, Toombs \& Waters 2003, Sharp \& Wheeler 2005, Fossum 2007).

Existem diferentes tipos de laminectomia, conforme o grau de exposição da medula espinhal, nomeadas de Funkquist $A$, Funkquist $B$ e laminectomia dorsal modificada (LDM) (Trotter 1996), esta última, indicada para a exposição de estruturas compressivas localizadas nas faces ventro-lateral e dorsal do canal vertebral como fragmentos de disco intervertebral, fragmentos de vértebras fraturadas, de neoplasmas extra e intra-durais e em compressões decorrentes da síndrome da cauda equina (Seim III 2005).

Algumas complicações podem ser encontradas em pacientes humanos (Lee et al. 1990) e animais (Jones et al. 2000, Da Costa et al. 2006) submetidos à laminectomia como a formação de fibrose epidural (FE) (Toombs \& Waters 2003, Almeida et al. 2008). Entre as principais sequelas pode-se citar a dor (Jones et al. 2000) e as deficiências neurológicas (Trotter et al. 1988, Da Costa et al. 2006). A FE ocorre devido às aderências mecânicas do tecido cicatricial fibroso com a dura-máter, raízes nervosas (Kemaloglu et al. 2003, Cabukoglu et al. 2004) e músculos epaxiais (Lee et al. 1990).

Além da FE, existe a possibilidade de compressão direta ocasionada pela musculatura adjacente à descompressão cirúrgica, como demonstrou um estudo de Nieto et al. (2005) com implante de malha de titânio para proteção da medula espinhal em ratos submetidos à extensa laminectomia (L1-L4). Os resultados apontaram que o implante auxiliou na redução de sinais clínicos neurológicos evitando lesão na medula espinhal por compressão direta dos tecidos moles adjacentes quando comparado ao grupo controle.
Poucas pesquisas têm sido desenvolvidas para demonstrar a influência dos tecidos moles na compressão medular, principalmente os músculos epaxiais adjacentes à medula espinhal após técnicas cirúrgicas descompressivas em cães. Logo, o objetivo deste experimento foi isolar, com auxilio de implante à base de alumínio, a musculatura epaxial (músculos espinhais, semiespinhal, interespinhal, longo dorsal e multífido lombar) da medula espinhal de cães submetidos à LDM e verificar se os músculos influenciaram na formação da fibrose epidural, na compressão medular e no aparecimento dos sinais neurológicos.

\section{MATERIAL E MÉTODOS}

Foram utilizados 10 cães hígidos, sem raça definida, entre 10 e 20 quilos, provenientes do Biotério Central da Universidade Federal de Santa Maria. Os cães foram submetidos a exame neurológico e estudo radiográfico simples da região toracolombar em busca de possíveis alterações que pudessem interferir no experimento. Após, foram distribuídos ao acaso em dois grupos de igual numero, denominados de grupo controle (GI) e grupo tratado (GII), e alojados em gaiolas individuais, por um período mínimo de adaptação de 15 dias recebendo água e ração comercial ad libitum. Este trabalho seguiu as normas de experimentação segundo o Comitê de Ética em Pesquisa da Instituição e aprovado conforme processo administrativo número 23081.011446/2008-78.

Todos os cães foram submetidos à cirurgia descompressiva de LDM. Para isto, os cães foram submetidos a jejum sólido e hídrico de 12 horas antes da cirurgia e realizada tricotomia ampla na região toracolombar dorsal. Os animais foram pré-medicados com cloridrato de morfina $\left(1 \mathrm{mg} \cdot \mathrm{kg}^{-1}\right)$, por via intramuscular (IM) e após 15 minutos, foi realizada punção da veia cefálica e a injeção de diazepam (0,3mg. $\left.\mathrm{kg}^{-1}\right)$, por via intravenosa (IV). Foi administrado propofol (4-6 mg. $\mathrm{kg}^{-1}$, IV) para a indução anestésica e manutenção com halotano, vaporizado em oxigênio a $100 \%$. Para a profilaxia bacteriana, foi utilizada cefalotina sódica (22mg. $\left.\mathrm{kg}^{-1}, \mathrm{IV}\right), 30$ minutos antes do início do procedimento cirúrgico e repetida a cada duas horas em bolus.

Os cães foram contidos em decúbito esternal seguido de anti-sepsia com álcool-iodo-álcool. A técnica de LDM foi então realizada entre as vértebras T13-L1, conforme recomendações de Toombs \& Waters 2003. A área do defeito sobre a lâmina óssea foi definida lateralmente pela remoção dos processos articulares caudais da vértebra T13 e craniocaudal pelo ponto médio das vértebras T13 e L1. O ponto médio foi localizado medindo-se o teto da vértebra em questão no sentido craniocaudal, com auxílio de um paquímetro para localização do ponto equidistante.

A diferença entre os grupos estudados foi que os cães do GII, após a exposição da medula espinhal pela LDM, receberam um implante à base de alumínio para isolá-la da musculatura epaxial. O implante foi preparado durante o procedimento cirúrgico, tendo seu comprimento definido pelo defeito ósseo adicionado de mais três milímetros e a largura determinada pelo defeito ósseo e distância entre os processos articulares craniais de L1. As extremidades laterais foram ampliadas em quatro milímetros, gerando o formato de ampulheta (Fig.1A,B), a fim de facilitar o envolvimento das vértebras $\mathrm{e}$ isolar a medula espinhal da musculatura epaxial (Fig.1C,D), permanecendo o implante no exterior do canal vertebral. 

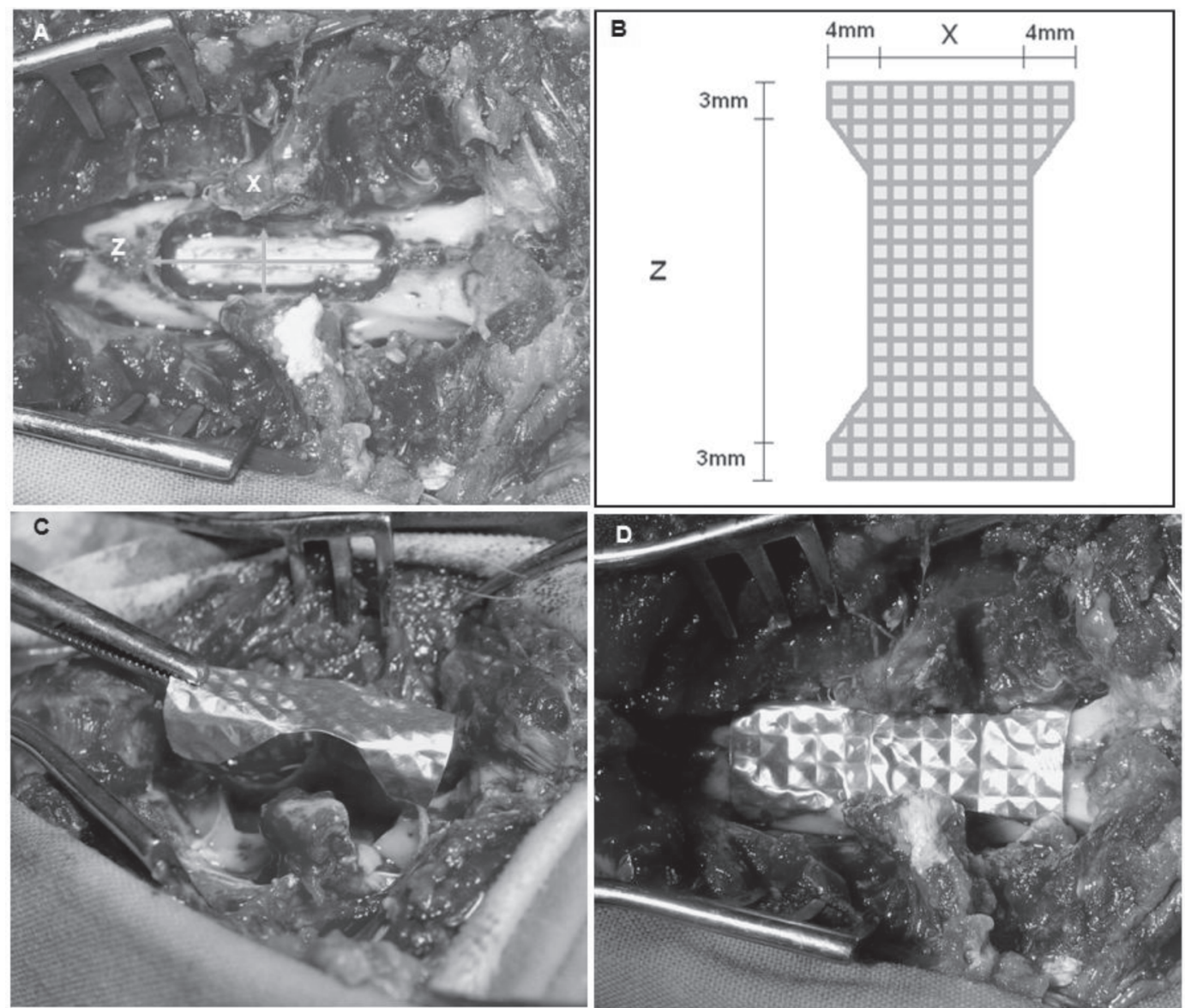

Fig.1. Laminectomia dorsal modificada em cão. (A) Dimensão da área resseccionada lateral $(X=$ seta menor) e comprimento ( $Z$ = seta maior). (B) Implante à base de alumínio com a dimensão lateral $(X+4 \mathrm{~mm}$ das extremidades laterais) e comprimento $(Z+3 \mathrm{~mm})$. (C) Colocação do implante à base de alumínio. Notar as dobras no implante para envolver as vértebras. (D) Implante colocado e moldado envolvendo a região dorsal e lateral das vértebras submetidas à laminectomia e isolamento da musculatura epaxial da medula espinhal.

Durante o procedimento cirúrgico foi quantificada a hemorragia proveniente dos ossos desgastados das vértebras e da musculatura epaxial e classificada como: 0 = ausência de ponto de hemorragia nas vértebras e na musculatura de forma difusa; $1=$ somente um ponto de hemorragia nas vértebras e ausente nos músculos; 2 = dois pontos de hemorragias nas vértebras e/ou muscular difuso; 3 = três pontos de hemorragias nas vértebras e/ou muscular difuso.

Após o procedimento cirúrgico, os cães receberam analgesia com cloridrato de morfina $\left(0,1 \mathrm{mg} \cdot \mathrm{kg}^{-1}\right)$, por via epidural, e $\left(0,3 \mathrm{mg} \cdot \mathrm{kg}^{-}\right.$ $\left.{ }^{1}\right)$ por via IM, decorridos 12 e 18 horas da cirurgia, e dexametasona $\left(0,25 \mathrm{mg} \cdot \mathrm{kg}^{-1}\right)$, por via IV, logo após a cirurgia, e $\left(0,1 \mathrm{mg} \cdot \mathrm{kg}^{-1}\right)$ por via IM, uma vez ao dia, durante dois dias. Curativos diários da ferida cirúrgica foram realizados com a utilização de gaze umedecida com solução de cloreto de sódio a 0,9\%.

Os cães foram submetidos às avaliações neurológicas, constituídas de reações posturais até 60 dias de $\mathrm{PO}$ e análise da marcha até 180 dias de PO. As disfunções neurológicas foram definidas mediante modificações daquelas classificadas por Griffiths (1982), sendo grau 0 - sem alteração neurológica; grau 1 = apenas dor à palpação epaxial; grau 2 = dor à palpação epaxial, ataxia proprioceptiva leve e discreta paraparesia; grau 3 = dor à palpação epaxial, incapacidade de locomover-se e acentuada paraparesia; grau 4 = dor à palpação epaxial, paraplegia, incontinência urinária e presença de dor profunda e grau 5 = dor à palpação epaxial, paraplegia, incontinência urinária e perda da dor profunda.

Os cães foram submetidos à mielografia por injeção de contraste na cisterna magna, nos dias 15, 30 e 60 dias de pósoperatório. Para a realização deste exame, os cães foram submetidos à anestesia geral, como descrito anteriormente. A técnica mielográfica foi realizada conforme descrito por Sharp \& Wheeler (2005). O contraste utilizado foi o iohexol $\left(0,5 \mathrm{ml} . \mathrm{kg}^{-1}\right)$, As incidências radiográficas realizadas foram látero-lateral, ventro-dorsal e ventro-dorsais oblíquas direita e esquerda da região toracolombar (T13-L1). As radiografias foram digitalizadas, com uso de câmera digital Canon A520, colocando-as sempre em um mesmo negatoscópio, redimensionadas pelo limite de 2,5 vértebras craniais e caudais ao espaço tóracolombar.

As imagens digitalizadas foram projetadas em monitor de 17 polegadas e interpretadas por dois radiologistas veterinários que realizaram análises sem conhecer em qual grupo o cão pertencia (estudo cego). A linha de contraste entre as vértebras T13-L1 foi comparada com duas vértebras craniais e caudais a este intervalo. As imagens foram classificadas como: 1 ou sem 
alteração = ausência de compressão medular na linha de contraste; 2 ou compressão leve = compressão inferior a 50\% da linha de contraste; 3 ou compressão moderada = compressão superior a $50 \%$ da linha de contraste; e 4 ou compressão grave = ausência da linha de contraste. Os resultados obtidos foram anotados e enviados para análise estatística.

Os cães foram submetidos à reintervenção cirúrgica, com a finalidade de verificar o isolamento e o grau de aderência entre musculatura epaxial e a medula espinhal, decorridos 180 dias PO. Com o cão em plano anestésico, conforme descrição anterior realizou-se o acesso a área da laminectomia e com auxílio de um elevador de periósteo foi rebatida, delicadamente, a musculatura epaxial e observada a existência de locais de contato entre a musculatura e a FE. O grau de aderência da FE entre a musculatura epaxial e a medula espinhal foi definido conforme Rydell (1970) e Butler et al. (1970), em: 1 = tecido cicatricial não aderido à dura-máter; 2 = tecido cicatricial aderido à dura-máter, mas facilmente dissecado; e 3 = tecido cicatricial aderido firmemente à dura-máter, e não possível de ser dissecado.

Para análise estatística do grau de compressão da medula espinhal e hemorragia no trans-operatório aplicou-se análise de variância (ANOVA) de uma via, seguida de teste de comparações múltiplas de Duncan. Todos os resultados foram indicados pela média \pm Erro Padrão da Média (EPM).

Foi realizado o teste Kappa (Fleiss 1973) para comparar a capacidade de concordância entre as avaliações das imagens radiográficas contrastadas interpretadas pelos avaliadores. Os valores obtidos foram classificados de acordo com a seguinte escala $(0-0,20)$ pobre; $(0,21-040)$ regular; $(0,41-0,60)$ moderada; $(0,61-0,80)$ boa; $(0,81-1,0)$ muito boa (Landis \& Koch 1977).

\section{RESULTADOS E DISCUSSÃO}

A técnica de LDM foi escolhida por mimetizar os casos de rotina em que se necessitam ampla exposição, como as mielopatias compressivas causadas por neoplasmas. A principal complicação cirúrgica foi os pontos de sangramentos na musculatura epaxial e nas vértebras resseccionadas, corroborando com as afirmações de Larocca \& Macnab (1974) e Songer et al. (1990). O grau de hemorragia durante a cirurgia foi menor nos cães do Grupo I quando comparado aos do Grupo II. Apesar da diferença não ser significativa, a hemorragia provavelmente contribuiu com a formação da FE, conforme encontraram os estudos de Songer et al. (1995).

O implante à base de alumínio foi de fácil obtenção, preparação e acomodação permitindo adequado isolamento da musculatura epaxial depois da exposição da medula espinhal pela laminectomia. Durante a sua colocação, foram envolvidas as superfícies dorsal e lateral das vértebras T13 e L1, visto que, Larocca \& Macnab (1974) citaram que a atividade fibroblástica ocorre na superfície da musculatura epaxial adjacente originando cicatriz fibrosa que se encaminha em direção às regiões dorsal e lateral da dura-máter. Embora o uso do implante não demonstre sinais clínicos de incompatibilidade, recomendam-se novos estudos com a finalidade de verificar a existência de toxicidade, reabsorção e biocompatibilidade.

Apenas um cão (GII) apresentou alterações neurológicas na marcha e deficiências neurológicas durante o período de avaliação, provavelmente pela manipulação cirúrgica. Estas alterações persistiram apenas durante os dois primeiros dias de PO. Toombs \& Waters (2003) e Sharp \& Wheeler (2005) citaram que após cirurgias descompressivas é comum que o animal apresente deficiências neurológicas com perda de até um grau de disfunção neurológica, principalmente devido à manipulação da medula espinhal.

A opção em utilizar o método de imagem digitalizada foi com base no estudo feito por Attaelmanan et al. (2000) que afirmaram inúmeras vantagens sobre o filme convencional, como a capacidade de melhorar a qualidade da imagem, aumentar áreas específicas (zoom) e facilitar o armazenamento em disquetes ou CDs. O grau de confiança entre os avaliadores do exame radiográfico foi de 0,514 e classificado como moderado.

Os resultados obtidos nesse estudo revelaram que, mesmo com o isolamento da musculatura epaxial da medula espinhal pelo implante à base de alumínio houve, em ambos os grupos, graus variados de compressão com diferença significativa $(P<0,05)$ somente aos 15 dias de pós-operatório. Isto pode sugerir que a musculatura epaxial não influenciou significativamente no grau de compressão da medula espinhal e no aparecimento dos sinais neurológicos.

A presença da fibrose epidural, embora existente, não ocasionou sinais clínicos persistentes e relevantes, diferente dos achados de Lee et al. (1990) os quais relataram que cerca de $15 \%$ dos pacientes humanos apresentam deficiências neurológicas após a realização da laminectomia, necessitando de reintervenção cirúrgica em $33 \%$ dos casos (Fritsch et al. 1996).

A realização de um novo procedimento cirúrgico, decorridos 180 dias de PO foi dificultado em ambos os grupos pela presença de tecido cicatricial, como salientado por Gill et al. (1985). No Gl foi observada aderência entre a musculatura e a fibrose cicatricial, corroborando com os achados de Lee \& Alexander (1984) e no Gll, o implante evitou o contato da musculatura epaxial com a fibrose isolando-a da medula espinhal.

Os cães dos Grupos I e II apresentaram grau 3 de adesão da medula espinhal à fibrose, corroborando com os resultados obtidos por Sun et al. (2008) em ratos. A complicação observada durante a avaliação da adesão cicatricial foi a lesão iatrogênica à dura-máter e consequente extravasamento de líquido cefalorraquidiano em três cães, porém, sem ocasionar deficiências neurológicas no pós-operatório. Estes achados coincidiram com os de Alkalay et al. (2003), Rodgers et al. (2003) e Massie et al. (2004) os quais comentaram que a fibrose epidural, além de tornar difícil a dissecação cirúrgica para acesso ao canal vertebral, aumenta as complicações trans-operatórias como a ocorrência de extravasamento dural, lesões de nervos espinhais e hemorragia local.

\section{CONCLUSÃO}

Com as condições descritas neste experimento, pode-se concluir que a musculatura epaxial adjacente é isolada 
da medula espinhal pelo implante à base de alumínio em cães submetidos à laminectomia dorsal modificada, e esta não influencia na formação da fibrose epidural, compressão medular e no aparecimento dos sinais neurológicos.

\section{REFERÊNCIAS}

Alkalay R.N., Kim D.H., Urry D.W., Xu J., Parker T.M. \& Glazer P.A. 2003. Prevention of postlaminectomy epidural fibrosis using bioelastic materials. Spine 28(15):1659-1665.

Almeida D.B., Prandini M.N., Awamura Y., Vitola M.L., Simião M.P., Milano J.B., Bordignon K.C., Ache M.P. \& Ramina R. 2008. Outcome following lumbar disc surgery: The role of fibrosis. Acta Neurochirurgica 150(11):1167-1176.

Attaelmanan A., Borg E. \& Grondahl H.G. 2000. Digitization and display of intra-oral films. Dentomaxillofacial Radiology 29:97-102.

Butler J., Rydell N.W. \& Balazs E.A. 1970. Effect of intra-articular injection of hyaluronic acid on the clinical symptoms of arthritis in track horses. Acta Vet. Scandinavica 11(2):139-155.

Cabukoglu C., Güven O., Yildirim Y., Kara H. \& Ramadan S.S. 2004. Effect of sagittal plane deformity of the lumbar spine on epidural fibrosis formation after laminectomy - an experimental study in the rat. Spine 29(20):2242-2247.

Da Costa R.C., Pippi N.L., Graça D.L., Fialho S.A., Alves A., Groff A.C. \& Rezler U. 2006. The effects of free fat graft or cellulose membrane implants on laminectomy membrane formation in dogs. Vet. J. 171:491499.

Fleiss J.L. 1973. Statistical Methods for Rates and Proportions. John Wiley \& Sons, New York, 233p.

Fossum T.W. 2007. Surgery of the thoracolumbar spine, p.1460-1492. In: Fossum T.W. (Ed.), Small Animal Surgery. $3^{\text {rd }}$ ed. Mosby, St Louis.

Fritsch E.W., Heisel J. \& Rupp S. 1996. The failed back surgery syndrome: reasons, intraoperative findings, and long-term results: A report of 182 operative treatments. Spine 21(5):626-633.

Gill G.G., Scheck M., Kelley E.T. \& Rodrigo J.J. 1985. Pedicle fat grafts for the prevention of scar in low-back surgery: A preliminary report on the first 92 cases. Spine 10(7):662-667.

Griffiths I.R. 1982. Spinal disease in the dog. In Practice 4(2):44-52.

Jones J.C., Banfield C.M. \& Ward D.L. 2000. Association between postoperative outcome and results of magnetic resonance imaging and computed tomography in working dogs with degenerative lumbosacral stenosis. J. Am. Vet. Med. Assoc. 216:1769-1774.

Kalfas I.H. 2000. Laminectomy for thoracic spinal canal stenosis. Neurosurgery Focus 9(4):1-3.

Kemaloglu S., Ozkan U., Yilmaz F., Nas K., Gur A., Acemoglu H., Karasu H. \& Cakmak E. 2003. Prevention of spinal epidural fibrosis by recombinant tissue plasminogen activator in rats. Spinal Cord 41:427431.
Landis J.R. \& Koch G.G. 1977. The measurement of observer agreement for categorical data. Biometrics 33(1):159-174.

Larocca H. \& MacNab I. 1974. The laminectomy membrane. J. Bone Joint Surg. 56B(3):545-550.

Lee C.K. \& Alexander H. 1984. Prevention postlaminectomy scar formation. Spine 9:305-312.

Lee H.M., Yang K.H., Han D.Y. \& Kim N.H. 1990. An experimental study on prevention of postlaminectomy scar formation. Yonsei Med. J. 31(4):359-366.

Massie J.B., Huang B., Malkmus S., Yakh T.L., Kim C.W., Garfin S.R. \& Akeson W.H. 2004. A preclinical post laminectomy rat model mimics the human post laminectomy syndrome. J. Neurosci. Methods 137:283289.

Nieto J.H., Hoang T.X., Warner E.A., Franchini B.T., Westerlund U. \& Havton L.A. 2005. Titanium mesh implantation: A method to stabilize the spine and protect the spinal cord following a multilevel laminectomy in the adult rat. J. Neurosci. Methods 147:1-7.

Rodgers K.E., Robertson J.T., Espinoza T., Oppelt W., Cortese S., Di Zerega G.S. \& Berg R.A. 2003. Reduction of epidural fibrosis in lumbar surgery with Oxiplex adhesion barriers of carboxymethylcellulose and polyethylene oxide. Spine J. 3:277-284.

Rydell N. 1970. Decreased granulation tissue reaction after installment of hyaluronic acid. Acta Orthopaedica Scandinavica 41:307-311.

Seim III H.B. 2005. Cirurgia da espinha toracolombar, p.1259-1291. In: Fossum T.W. (Ed.), Cirurgia de Pequenos Animais. $2^{\underline{a}}$ ed. Roca, São Paulo.

Sharp N.J.H. \& Wheeler S.J. 2005. Small Animal Spinal Disorders: Diagnosis and surgery. $2^{\underline{a}}$ ed. Elsevier Mosby, Philadelphia. 380p.

Songer M.N., Ghosh L. \& Spencer D.L. 1990. Effects of sodium hyaluronate on peridural fibrosis after lumbar laminotomy and discectomy. Spine 15:550-554.

Songer M.N., Rauschning W., Carson E.W. \& Pandit S.M. 1995. Analysis of peridural scar formation and its prevention after lumbar laminotomy and discectomy in dogs. Spine 20(5):571-580.

Sun Y., Wang L., Sun S., Liu B., Wu N. \& Cao X. 2008. The effect of 10hydroxycamptothecine in preventing fibroblast proliferation and epidural scar adhesion after laminectomy in rats. European J. Pharmacol. 593:44-48.

Toombs J.P. \& Waters D.J. 2003. Intervertebral disc diseases, p.11931209. In: Slatter D. (Ed.), Textbook of Small Animal Surgery. $3^{\text {rd }}$ ed. Saunders, Philadelphia.

Trotter E.J., Crissman J. \& Robson D. 1988. Influence of nonbiologic implantes on laminectomy membrane formation in dogs. Am. J. Vet. Res. 49(5):634-643.

Trotter E.J. 1996. Laminectomia dorsal para o tratamento da discopatia tóraco-lombar, p.572-584. In: Bojrab M.J., Birchard S.J. \& Tomlinson J.L. (Eds), Técnicas Atuais em Cirurgia de Pequenos Animais. $3^{\underline{a}}$ ed. Roca, São Paulo. 